\title{
Biceps Femoris
}

National Cancer Institute

\section{Source}

National Cancer Institute. Biceps Femoris. NCI Thesaurus. Code C53147.

A muscle in the back of the thigh. Its action involves the knee flexion and hip extension. 